\title{
Cold snare piecemeal endoscopic mucosal resection of a very large duodenal adenoma
}

An 83-year-old woman was referred for the management of an incidentally found large duodenal polyp. The polyp was biopsied by the referring physician and was found to be a tubulovillous adenoma. The patient was scheduled for esophagogastroduodenoscopy with endoscopic mucosal resection (EMR).

The procedure was performed under general anesthesia, using a therapeutic upper endoscope and duodenoscope. A $6-\mathrm{cm}$ polyp was visualized in the second part of the duodenum ( $\mathbf{F i g . 1}$ ), $1 \mathrm{~cm}$ proximal to the major papilla. The polyp involved $60 \%$ of the luminal circumference. No depressed or ulcerated areas were noted upon examination with high-definition white-light and narrowband imaging. The polyp was injected submucosally with a 1:200000 solution of epinephrine in saline and methylene blue ( $\boldsymbol{F i g . 2}$ ). Piecemeal cold snare EMR was performed using a 9-mm cold snare (Exacto; US Endoscopy, Mentor, Ohio, USA). The total procedure time was 2 hours 30 minutes; an advanced endoscopy fellow assisted with the procedure, resulting in a somewhat extended procedure time. The entire polyp was removed ( $\triangleright$ Fig. 3 ), and resected fragments were suctioned through the endoscope channel and retrieved completely. Minimal self-limited oozing was noted from the resection site, but did not require any treatment.

The patient recovered well following the procedure, without any complications. Pathology showed a tubulovillous adenoma without high grade dysplasia.

The patient returned for surveillance 3 months later. During surveillance endoscopy, a 12 -mm residual polyp was noted, which was resected using piecemeal cold snare resection, with good results ( Fig.4).

This case demonstrates the successful use of a cold snare piecemeal EMR technique for a large periampullary duodenal adenoma/polyp. This technique is well

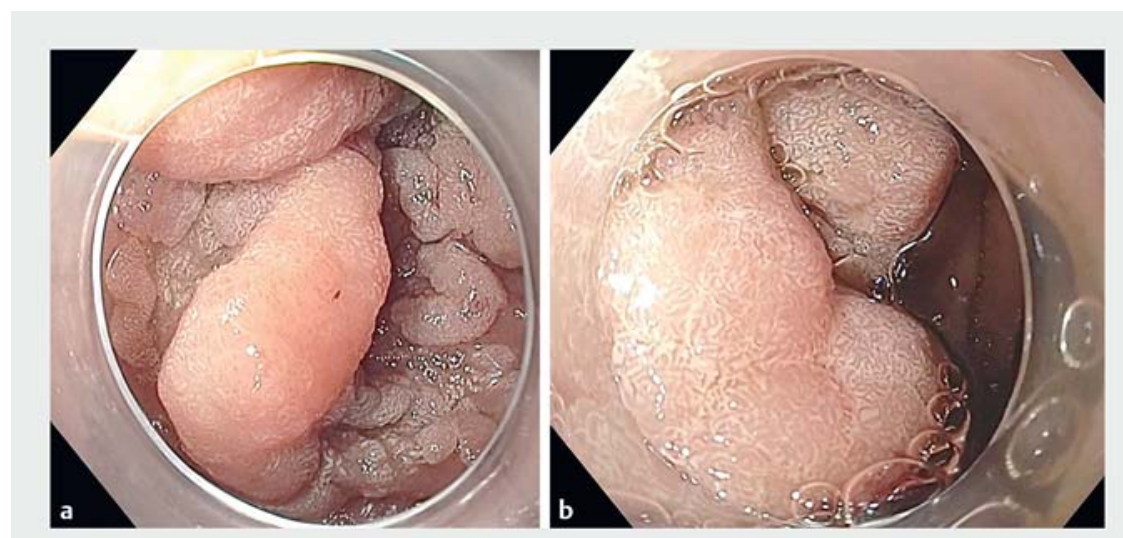

- Fig. 1 Duodenal polyp. a, b The polyp was visualized in the second part of the duodenum.

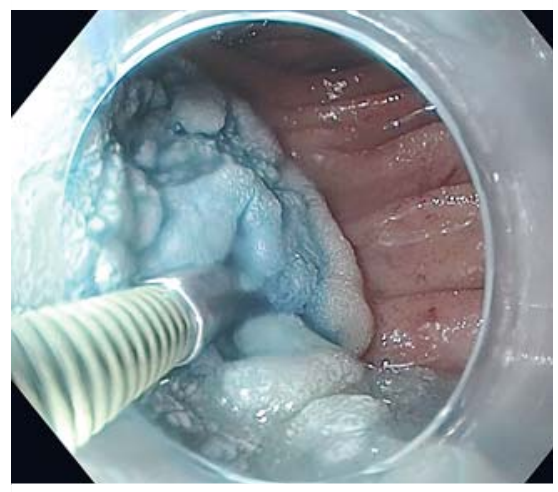

Fig. 2 Submucosal injection of the polyp.

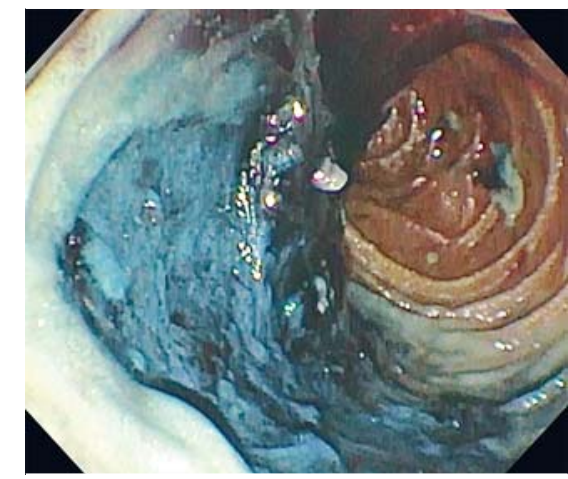

- Fig. 3 The resection base after cold snare endoscopic mucosal resection.
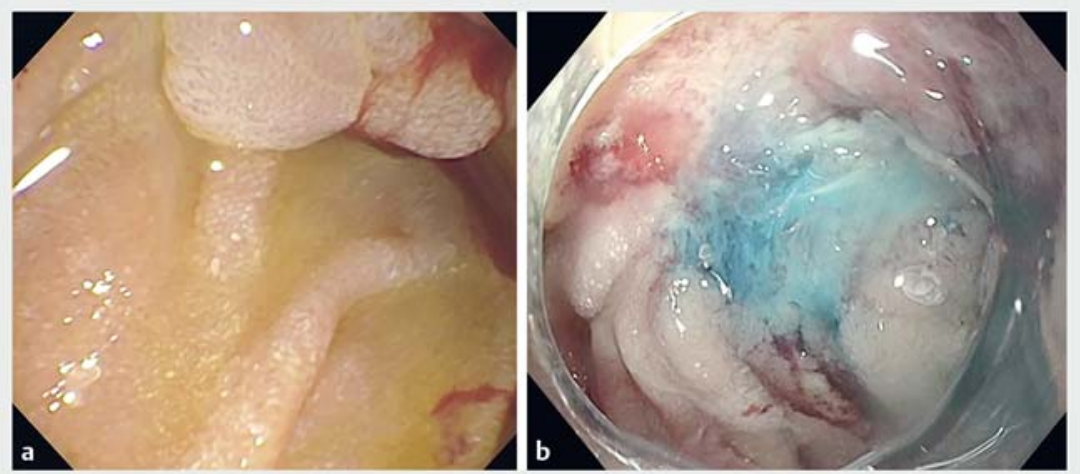

- Fig. 4 Surveillance endoscopy. a A residual polyp was found during surveillance. $\mathbf{b}$ The resection base after removal of the residual polyp 


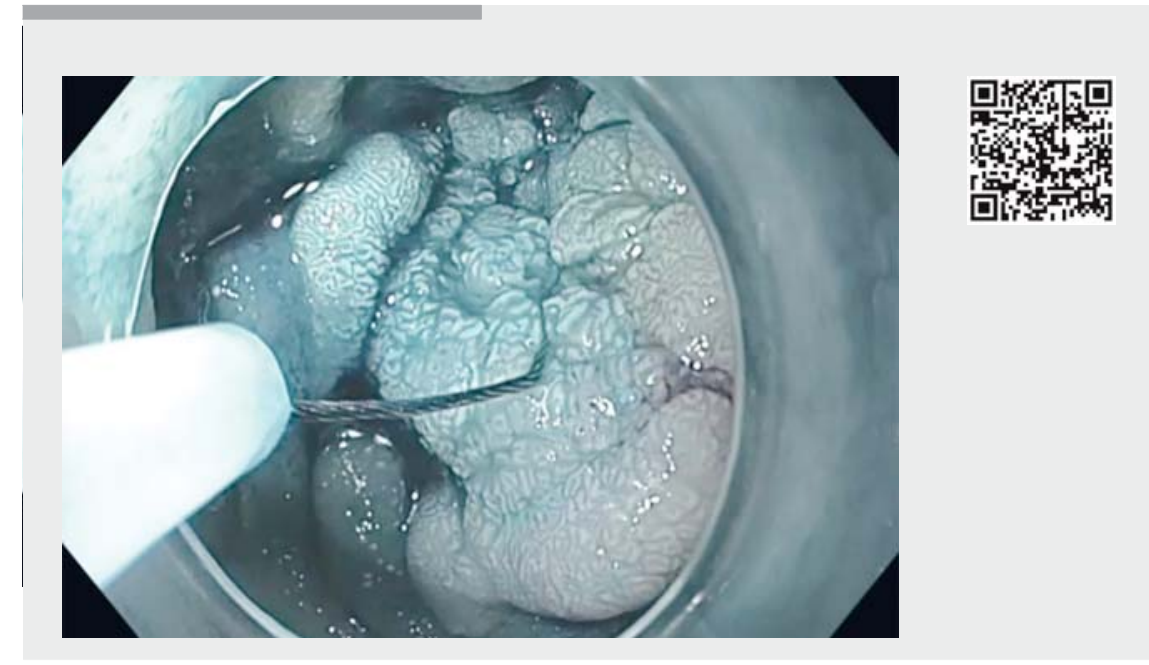

Video 1 Cold snare piecemeal endoscopic mucosal resection of large periampullary duodenal adenoma.

described for large colon polyps where it has been found to have extremely low complication rates [1]. In contrast, high complication rates have been reported for hot snare EMR of duodenal polyps [2]. The cold snare technique could be considered preferentially for the resection of large duodenal polyps in order to minimize complication rates.

Endoscopy_UCTN_Code_TTT_1AO_2AG

\section{Competing interests}

None

\section{References}

[1] Piraka C, Saeed A, Waljee AK et al. Cold snare polypectomy for non-pedunculated colon polyps greater than $1 \mathrm{~cm}$. Endosc Int Open 2017; 5: E184

[2] Pérez-Cuadrado-Robles E, Quénéhervé L, Margos W et al. Comparative analysis of ESD versus EMR in a large European series of non-ampullary superficial duodenal tumors. Endosc Int Open 2018; 6: E1008-E1014

\section{Bibliography}

DOI https://doi.org/10.1055/a-0875-3838

Published online: 30.4.2019

Endoscopy 2019; 51: E217-E218

(c) Georg Thieme Verlag KG

Stuttgart · New York

ISSN 0013-726X

\section{ENDOSCOPY E-VIDEOS}

https://eref.thieme.de/e-videos

\section{Siddharth B. Javia, Krishnavel Chathadi}

Department of Internal Medicine, Division of Gastroenterology and Hepatology, Henry Ford Health Systems, Detroit, United States

\section{Corresponding author}

\section{Siddharth B. Javia, MD}

Department of Gastroenterology, Wenatchee Valley Hospital and Clinics Campus, 820 N. Chelan Ave, Wenatchee, WA 98801, USA

Fax: +1-509-664-3438

sidbj00@gmail.com 